\title{
Musculación y los nuevos valores estéticos en la narrativa social hispana contemporánea
}

Bodybuilding and new aesthetic values in contemporary hispanic social narrative

\author{
Ramiro Aurelio Buitrago ${ }^{1}$; Yulianna Lobach²; Carlos Daniel Henríquez Jiménez ${ }^{3}$; \\ Isabel Portillo 4 \\ ${ }^{1}$ Alcaldía Bolivariana de Miranda, Maracaibo, Venezuela \\ http://orcid.org/0000-0002-8563-7662 \\ ${ }^{2}$ Quality Leadership University, Panamá, Panamá \\ https://orcid.org/0000-0001-7126-6808 \\ ${ }^{3}$ Universidad Privada Dr. Rafael Belloso Chacín, Maracaibo, Venezuela \\ http://orcid.org/0000-0002-8668-7768 \\ ${ }^{4}$ Universidad Privada Dr. Rafael Belloso Chacín, Maracaibo, Venezuela \\ http://orcid.org/0000-0001-5110-5302
}

\author{
Detalles del artículo: \\ Número de palabras: 15.247; Tablas: 0; Figuras: 0; Referencias: 33 \\ Recibido: julio 2021; Aceptado: agosto 2021; Publicado: diciembre 2021 \\ Conflicto de interés: El autor declara que no existen conflictos de interés. \\ Correspondencia del autor: Ramiro Aurelio Buitrago,dr.buitrago86@gmail.com
}

\section{Resumen}

El presente estudio tuvo como propósito, comprender desde un enfoque socioantropológico, el trasfondo cultural que permea al ejercicio físico, al interior de los centros de musculación y entrenamiento con pesas, donde se reconstruyen los cuerpos masculinos, bajo la égida de la fuerza, virilidad y estética. En este extenso se aprovechó el diseño documental y el método hermenéutico-dialéctico, donde la documentación y la matriz bibliográfica fueron los instrumentos utilizados. Su elaboración, estuvo apoyada en la batería documental propuesta por autores como: Morales (2020), Martínez (2020), Vilas (2019), y Ocampo (2019), entre otros. Completada la confrontación de los contenidos seleccionados para tal fin, pudo a grandes rasgos contemplarse el comportamiento humano y social, manifestado por los hombres que se dedican a cultivar su físico desde la otredad, al mismo tiempo, se reflexionó sobre los intereses que les conduce en su alteridad a integrarse en la comunidad de pesistas. Pudo concluirse, que la sociedad hispana contemporánea procura reconocer en el varón, valores estéticos recargados de tradición eurocentrista, pues en su personificación y corporeidad el modelo masculino se adhiere a los esquemas clásicos de la belleza blanca.

Palabras claves: Iconos Sociales, estética, belleza blanca, Hispanoamérica, eurocentrismo. 


\section{Abstract}

The purpose of this study was to understand from a socio-anthropological approach, the cultural background that permeates physical exercise, inside the centers of bodybuilding and weight training, where male bodies are deconstructed, under the aegis of strength, virility and esthetic. In this extensive documentary design and the hermeneutical-dialectical method were used; where the documentation was the applied technique and the bibliographic matrix, as well as the analytical content matrix, the instruments used. Its elaboration was supported by the documentary battery proposed by authors such as: Morales (2020), Martinez (2020), Vilas (2019), and Ocampo (2019), among others. After completing the confrontation of the contents selected for this purpose, it was possible to broadly contemplate the human and social behavior, manifested by the men who dedicate themselves to cultivating their physique from otherness, at the same time, they reflected on the interests that lead them in their alterity to integrate into the community of weightlifters. It could be concluded that contemporary Hispanic society seeks to recognize in the male aesthetic values loaded with Eurocentric tradition, since in the personification and corporeality of him the male model adheres to the classic schemes of white beauty.

Key words: Social Icons, esthetics, white beauty, Latin america, eurocentrism.

\section{INTRODUCCIÓN}

Para nadie es un secreto que durante siglos se le ha considerado al hombre blanco, como arquetipo estético superior en un sentido amplio. Más allá del elemento discriminativo, racial e incluso xenófobo, que no conviene, ni interesa abordar en el presente extenso; es bien sabido, que los cánones sociales que esquematizan el ideal de belleza masculina a nivel mundial, están sesgados a favor de la piel blanca. Partiendo de allí, se ha desencadenado un inconmensurable torbellino de fenómenos de orden social, cultural, consuetudinario, artístico, estético, filosófico, político e incluso religioso y deportivo, que han tenido como célula fundamental, la maximización de la belleza blanca por más de quinientos años, lo que aún entonces continúa filtrándose en diversos escenarios del contexto contemporáneo, advirtiendo que lo expuesto, comprende al arco ideático concebido e impuesto por el pensamiento eurocentrista, mismo que emergió como consecuencia al renacimiento y los postulados generados por los artistas, estetas y pensadores con origen en Europa meridional desde principios del siglo XV.

Ahora bien, el interés por la belleza masculina no es algo nuevo, ni ajeno a la realidad social contemporánea, menos aún para el ser humano de forma individual, pues el sentido y juicio otorgado a la belleza, ostenta un carácter innato en cada persona, nadie enseña a nadie a percibir la belleza como tal, pues cada quien manifiesta atracción o desagrado frente a aquello que logra ver, escuchar, percibir a través de sus sentidos. Desde que el hombre es niño, desarrolla de forma autónoma su sentido del gusto y sus preferencias estéticas, ante lo que para sí mismo resulta hermoso. De allí, que en los primeros años de infancia, el individuo manifieste predilección por cierto color, y comience a decantarse por todo aquello que sea de ese mismo tono, pues es lo que desde su visión personal, le hace sentir mejor y experimentar mayor agrado. Santo Tomás de Aquino (1225 - 1274) alguna vez dijo... Bello es todo aquello que atrae y 
agrada a nuestros sentidos... y es verdad, como individuos cada persona desarrolla sus propios cánones de belleza, desde la otredad, sí, pero validando sus propios valores estéticos.

De conformidad con lo anterior, conviene indicar que los valores estéticos, se erigen como virtudes que emanan de cada persona, muestra artística, pictórica, teatral, dancística, musical, así también se involucra en ello a los animales de cualquier tipo, por lo general cuando ostentan características físicas y/o visuales muy vistosas; más allá de ello, pudiera considerarse incluso a la moda, y los eventos que se relacionan con esta, todo lo cual puede enriquecer o no a la persona, desde el halo filosófico de cada individuo; el que bien puede responder con sus respectivas reacciones o apreciaciones, a favor o en contra de aquello que aprecie a través de sus sentidos, recordando que estos valores estéticos son básicamente: Belleza, Equilibrio, Armonía, Tragedia y Horribilidad, entre otros, todos y cada uno, pueden representar para el hombre la satisfacción o el desagrado, según sus propias exigencias y estamentos estéticos intrínsecos, pues vale recordar que la estética en sí misma, no es un tema sólo de belleza, es también una rama de la filosofía, ya que no todo sobre la belleza es superficialidad y frivolidad, también es ciencia.

Igualmente, conviene tener en cuenta que, al reconocerles como un tipo de valor, dichos valores estéticos, terminan convirtiéndose en esquemas sociales, como criterios o escalas referenciales comunes y compartidas por determinado grupo social, lo cual deja entrever que los valores estéticos cambian de una región a otra, de un país a otro, de una a persona. Del mismo modo, resulta válido reiterar que la estética involucra la percepción de los sentidos... e igualmente, se relaciona con la filosofía de lo que se reconoce como bello. Así pues, conviene plantear que los valores estéticos se desprenden de las apreciaciones o juicios de valor, de quienes se auto reconocen como estetas y más allá de ello, de cualquiera que sepa reconocer la belleza; vale acotar que en este extenso, se hace referencia a la belleza exterior, aquella que de forma exclusiva y absoluta, solo puede ser percibida y reconocida por los sentidos, a raíz de un conglomerado de reflexiones filosóficas, estéticas y éticas sobre aquello que resulte bello.

En ese sentido, pudiera decirse que los valores estéticos, varían según la percepción que cada persona tenga sobre alguna persona, animal o cosa en específico. O sea, que lo que es bello para alguien, puede no serlo para otro. Sin embargo, más allá de desarrollar un constructo epistémico, que aborde a la estética como rama de la filosofía, es necesario establecer nexos entre los valores estéticos, la estética y la musculación como sendero hacia un ideal de belleza masculina, compartido por un grupo o comunidad de varones con presencia en diferentes regiones del mundo, quienes a pesar que muchas veces no comparten el mismo origen, nivel de instrucción, estrato social, orientación sexual, idioma o etnia, todos ellos persiguen transformar su entidad corpórea, ajustándole a modelos estéticos específicos. Es decir, que con la musculación, y otras disciplinas deportivas como la halterofilia, el fisicoculturismo, el físico constructivismo y el fitness, muchos hombres en Hispanoamérica persiguen alcanzar un ideal físico, que desde sus valores estéticos compartidos le consideran perfectamente hermoso.

Ante lo descrito en los párrafos anteriores, ha quedado claro que dichos valores estéticos, comprenden un conglomerado de procesos, que además de ser objeto de estudio por parte de la estética, resultan ser también una rama de la filosofía, donde se teoriza y delimitan las fronteras entre la belleza y la fealdad... según el criterio de cada quien. Pensadores y filósofos como Pitágoras, Sócrates, Platón, elaboraron cada uno sus propios constructos sobre 
la estética o los valores estéticos, lo cual deja claro que estos comprenden un fenómeno multidimensional atemporal, como elemento integral en la humanidad del ser humano pensante y racional, con la capacidad de reconocer, decantarse por aquello que le resulte bello, hermoso, agradable. Por ello, es de inferir que los valores estéticos, se sustentan en los principios éticos y morales de otros valores humanos, sociales, culturales. De allí, que hayan sido explorados por investigadores en áreas como la sociología, antropología, psicología, educación, comunicación, así como las ciencias del arte y el deporte.

Ahora bien, estos valores estéticos a los que se ha hecho referencia durante todo el discurso, configuran los criterios, con los que cada persona logra manifestar laudos, sobre aquello que resulta de su agrado, admiración o desagrado; siempre que tenga oportunidad de apreciar una obra, deporte, persona, objeto, animal, entre otros. Esta capacidad del ser humano, de reconocer lo que desde sus propios valores estéticos le parezca bello, tuvo origen con el hombre mismo, es decir, los valores estéticos forman parte de la humanidad desde que esta existe. Como ejemplo de ello, pudiera tenerse en cuenta al hombre de Neandertal, que habitó en Europa y Asia en el paleolítico medio, entre el 130.000 y el 33.000 a. de C., así como al hombre de Cromagnon el cual ocupó Europa en el paleolítico superior, entre el 35.000 y el 10.000 a. de C., quienes desde su primitivo sentido de la estética, procuraban adornar su apariencia, intentando destacarse entre tantos otros hombres, y resultar vistosos o atractivos a la hembra, con la finalidad de atraerle y poder reproducirse con esta. Es decir, que los valores estéticos, han acompañado a la humanidad desde el principio de los tiempos, pudiera decirse incluso que son inherentes al hombre, tanto como lo es su personalidad.

Por ello, al estudiar en el contexto contemporáneo, la concepción de la belleza masculina hispanoamericana, su relación estrecha con la musculación, y las diferentes disciplinas deportivas con pesas; conviene tener muy claro en qué consisten estos valores estéticos, que los varones de gimnasio comparten como comunidad específica, entre los que se cuentan: la belleza en la hipertrofia muscular, el magnetismo del deporte, la grandiosidad en la superioridad física, la pulcritud en la piel blanca, la armonía en las formas masculinas y la estructura física robusta, entre otros tantos que varían de una región y otra, pero que en esencia, procuran personificar en su corporalidad los ideales impuestos desde eurocentrismo, la figura atlética del hombre europeo de origen griego, itálico, ibérico; donde las formas se ajustan a cuerpos de gran estatura, piel lechosa y musculatura robusta, teniendo como referente histórico al gladiador romano o el atleta griego, centrando gran interés en la masculinidad absoluta. Con relación a ello, Morales (2020), ha referido lo siguiente:

Lo masculino es el estándar mundial, incluso para denominar al ser humano decimos hombre. Analizar la estructura del cuerpo masculino heterosexual como mercancía en la industria cultural y en la comunicación, da paso a visibilizar las formas de concebir la sexualidad en la industria del sexo. Estas formas se reducen a ciertos factores pensados desde el hombre para el hombre. (p. 02)

Desde su lugar, Martínez (2020), ha expuesto que: "La construcción simbólica del macho, comprende un conglomerado de elementos de índole cultural. Como arquetipo, el macho en Occidente es caracterizado y reconocido por su fuerza física, su virilidad y una posición social relevante, que le otorgue cierto o gran dominio, sobre otros hombres y en especial sobre la mujer, desde un enfoque heteronormativo, patriarcal, falo centrista y 
anacrónico" (p. 276). De lo anterior, puede reconocerse el alcance, importancia y relevancia, que ha adquirido para la sociedad hispana contemporánea, la apariencia física masculina, siempre que se ajuste a los estándares de virilidad superior a la media. Todo lo cual genera gran disconformidad, teniendo en cuenta que el hombre hispano, físicamente no suele ser ni muy alto, ni muy robusto, ni muy blanco. Coincidiendo en ello con el referido autor, los investigadores Buitrago, Vera, Henríquez y Gutiérrez (2021), han agregado lo siguiente:

En los últimos años ha adquirido gran relevancia la apariencia física, porque aunque no sea lo único que tiene para ofrecer una persona, es muy cierto que la cara y el cuerpo, son elementos de repercusión inicial en la impresión que ésta genere. (p. 44)

Así entonces, en los contenidos que se presentan en este extenso, se procura establecer vínculos entre la musculación, así como otras prácticas deportivas con pesas, y la personificación de los modelos sociales contemporáneos, concibiendo al varón ideal como un hombre blanco, de fuerza y estructura muscular superior, glorificando así a la estética masculina eurocentrista. Ahora bien, ¿Cómo se concibe la masculinidad y la masculinización del varón en Hispanoamérica?, para atender esta interrogante, pudiera tenerse en cuenta lo que desde su lugar Faur (como se citó en Buitrago et, al., 2021), ha expuesto: "La masculinidad es una construcción cultural que se reproduce socialmente y, por ello, no puede definirse fuera del contexto social, económico e histórico" (p. 44). Con referencia a ello, es el autor Barco (como se citó en Morales, 2020), quien ha referido lo siguiente:

El poseedor del dominio tradicionalmente lo tiene el hombre. Sobre la mujer existen ideas preconcebidas que no se dieron a partir de su consentimiento, más bien, fueron pensadas e impuestas a partir de las necesidades del hombre. Las estructuras sociales están cimentadas en la heterosexualidad. [...] por lo tanto la heteronormatividad dentro de este discurso juega un papel clave, al ser convertida en algo universal, intemporal e invencible. (p. 04).

De acuerdo con lo anterior, a la figura masculina se le ha otorgado un valor superior al de la mujer, las líneas de pensamiento eurocentrista glorifican al hombre y manda al fondo a las féminas, el discurso sociocultural, que desde la colonización del pensamiento hispanoamericano, se ha manejado en los países de habla hispana, elevan al hombre [sobre todo si se trata de un hombre blanco] como la figura con mayor dominio social. En su opinión, Morales (2020), ha referido que: "Este orden social dominado por el principio masculino, está dado de tal modo, que es difícil reconocer que la mayoría de las prácticas y percepciones no son más que constructos sociales" (p. 05). Estos constructos, se han filtrado al escenario deportivo y es por ello que... aun cuando se tenga conocimiento de numerosas atletas y femeninas de renombre internacional, usualmente son glorificados los deportistas varones a través los medios de comunicación masiva, como referentes sociales de alta estima, modelos a seguir para jóvenes y adolescentes, en pocas palabras los atletas y deportistas masculinos se han convertido en los nuevos gladiadores de la sociedad contemporánea.

Ahora bien, en los países de habla hispana, los ideales de belleza masculina se desprenden y distancian de sus raíces autóctonas, pues en estos son habitualmente reconocidos como más bellos, los hombres que aun siendo hispanos, ostentan características físicas mucho más globales, por no decir, eurocéntricas o de herencia genética ibérica; aunque el hombre de 
a pie continúa siendo en su mayoría de tez morena, mulata o de color. En los medios de comunicación masiva, así como en la industria cultural y del entretenimiento, se continúa elevando a niveles superiores al hombre blanco, cuya estatura, estructura física y muscular supera a la media del hispano. De hecho, en los últimos años, la estética facial masculina en la cultura popular, ha experimentado una transformación hacia el modelo ibérico, nariz fina, ángulos más redondos, y rostros pilosos, exageradamente pilosos. Lo anterior, ha sido consecuente a la masificación de contenidos visuales, generados desde los países nórdicos, donde con frecuencia se aplican valores estéticos orientados por el eurocentrismo y los roles principales o de mayor impacto, son en su mayoría personificados por varones de origen nórdico. Al respecto, Simpson (como se citó en Ocampo, 2019b), plantea lo siguiente:

En la década de los noventa, emergió el concepto de metrosexual, ahora el término spornosexual, es la tendencia del momento, con el se hace referencia a la importancia que tiene el deporte y el mundo del porno en la mente del hombre, hacia la construcción idearía del cuerpo masculino, donde este se convierte en un espectáculo en sí mismo. (p. 130)

De acuerdo a ello, autores como Buitrago et al,. (2021), han expuesto que: "Desde el enfoque histórico, tanto el cuerpo como el rostro masculino y los elementos que les singularizan o diferencian de un hombre a otro, corresponden a una figura antropológica y social definida, única e indivisible de quien los porta" (p. 44). Lo anterior, embarga relación con el presente estudio, pues aunque en este particular, se procura establecer vínculos entre la musculación y los nuevos modelos sociales, puede reconocerse, que finalmente la representación corpórea de todo a lo que se ha hecho referencia, se refleja en la personificación del hombre hispano contemporáneo, como atleta que se entrena de forma constante; ejercitándose con pesas, ejecutando prácticas que van de la halterofilia al fisicoculturismo y el fitness, procurando robustecer su musculatura, maximizando con ello sus características físicas más masculinas y robusteciendo así su entidad corpórea, procurando hacerse sexualmente más atractivos. Con respecto a ello, Aguiar de Souza (como se citó en Ocampo, 2019b), plantea lo siguiente: "En las últimas décadas se han producido variaciones en los referentes culturales de la masculinidad, donde el cuerpo masculino ha recuperado paulatinamente el carácter de objeto erótico que pudo tener en algún momento de la antigüedad" (p. 130).

Con atención a lo planteado en los párrafos anteriores, Morales (2020), sostiene lo siguiente: "Los roles de poder continúan reproduciéndose en las nuevas narrativas audiovisuales, y generan nuevas formas de enajenación estrictamente relacionadas al consumo del cuerpo" (p. 12). El cuerpo masculino se ha convertido en un referente de poder, a mejor estado físico, mayor impacto social; los hombres con mejor figura, son reconocidos como especímenes superiores, lo que trae a colación la idea de la rutina deportiva, la alimentación rica en proteínas y carbohidratos, el entrenamiento físico con pesas: musculación. Respecto a ello, Le Breton (como se citó en Sossa, 2015), ha referido que: "En la cultura deportiva, se persigue la deconstrucción del cuerpo masculino, y en esa búsqueda, se descubren placeres no imaginados, encontrando gozo en el dolor como producto de la actividad deportiva, donde la transpiración y el cansancio significan esfuerzo y poder" (p. 141).

Teniendo en cuenta lo descrito a esta altura del extenso, pudiera reconocerse en el cuerpo masculino, el nuevo objeto de culto para la sociedad contemporánea, como 
manifestación de la superioridad del varón blanco o la expresión de la personalidad del hombre, una representación gráfica y tridimensional de su estilo de vida o como monumento a la nueva masculinidad, donde la mejor forma de rendirle gloria, es a través del ejercicio físico y las prácticas deportivas con pesas como la musculación, ante lo cual, autores de la talla de Maffesoli (como se citó en Ocampo, 2019b), refiere lo siguiente: "El cuerpo de las personas aparece como un espacio en donde éstas identifican su identidad, la cual está influenciada y guiada por el discurso del consumo" (p. 127).

Así entonces, la musculación como disciplina deportiva, ha adquirido preponderancia en los últimos años. Diariamente, son más los varones que se integran a las comunidades fitness, pues reconocen en tales prácticas un escenario donde desenvolverse como líderes, o bien como hombres que se preocupan por verse bien. Tanto la musculación, como el fisicoculturismo y el fisicoconstructivismo, son disciplinas que más allá de perseguir la salud y su equilibrio con el aspecto físico, procuran el incremento de la masa muscular, la armonía entre cada grupo muscular, y el embellecimiento de las formas que más realzan al cuerpo del varón. Del mismo modo, Maffesoli (como se citó en Ocampo, 2019b), plantea que: "La estética del cuerpo masculino robusto y muscular, se ha promovido desde los medios de comunicación, fomentando así arquetipos y referentes no corporales, enmarcados en el cuidado del cuerpo y la búsqueda de la juventud eterna, generando la reedición contemporánea del culto al cuerpo" (p. 127). Por su parte, Cortazar (2009), ha referido que:

El cuerpo, en el mundo contemporáneo, es una arcilla, moldeable a voluntad, donde cada quien puede aspirar al auto-moldearse el cuerpo que desee, a condición de imponerse la disciplina necesaria para lograrlo. Pero el cuerpo hoy no es sólo mercado, es ante todo un fenómeno social y cultural de gran envergadura, objeto digno de ser mostrado, exhibido, visto, comercializado, mejorado, moldeado e incrementado a voluntad. Instrumento de comercialización y contemplación, vehículo de representaciones colectivas de la nación y de la política, no exento de conflictos y negociaciones. (p. 11)

De ahí, que los valores estéticos sean considerados como un fenómeno multidimensional, que merece ser atendido, auscultado y reconocido por distintas ciencias, en más de un estudio académico e incluso científico; pues además de ser objeto de interés para los investigadores en filosofía, psicología, sociología, antropología, educación; vale acotar que también de ellos se desprenden aristas, que irrumpen en cualquier contexto, donde las ciencias del deporte, las ciencias del arte, la comunicación y el mercadeo, pudieran identificar elementos que robustezcan los procesos ya existentes; generando así nuevos enfoques para el abordaje de escenarios integrales, donde los valores a los que se ha hecho referencia en el presente extenso, respondan a las preguntas para las que aún no se haya encontrado contestación, o mejor aún, brinden respuestas diferentes e innovadoras a interrogantes ya atendidas.

\section{COMPONENTE METODAL}

Se más indicado en la aproximación científica de los fenómenos sociales, con el interés de comprenderles. Es así, como con apoyo al modelo cualitativo se abordó un proceso social complejo, donde se reconocieron vínculos entre los valores estéticos, la musculación y los nuevos modelos sociales de donde emergen arquetipos contemporáneos, como aquellos que 
atienden a la masculinidad. El presente estudio se apoyó en el diseño documental y el método hermenéutico-dialéctico, mismos que fueron la brújula epistemológica de las acciones acometidas por los investigadores. En ese sentido, conviene destacar que en el presente extenso, se socializan los descubrimientos y redescubrimientos iniciales de un procedimiento investigativo formal, donde la fase inicial comprendió, tanto la indagatoria documentaria, como la discriminación y selección de fuentes originales, sustento epistémico de los hallazgos finales.

Según López (2002), es importante tener presente lo siguiente: "El modelo cualitativo surge como alternativa al paradigma racionalista, puesto que en las disciplinas de ámbito social existen diferentes problemáticas, cuestiones y restricciones que no se pueden explicar, ni comprender en toda su extensión desde la metodología cuantitativa" (p. 168). En este estudio, se hizo abordaje a un evento social, que en los últimos años ha dado mucho de qué hablar, e igualmente ha generado interés, esencialmente en el ámbito comercial, por tratarse de una industria que genera grandes riquezas monetarias, como lo es la de la belleza o el cuidado físico. Sin embargo, es preciso recordar, que todo aquello en lo que se involucra a los estamentos y formas sociales, es susceptible de ser indagado por los investigadores en ciencias humanas, sociales y del deporte.

Al respecto Prada (2018), ha expuesto lo siguiente: "La investigación cualitativa permite al investigador trabajar, interpretar e involucrarse desde varias perspectivas y disciplinas. En esta línea, es flexible, pues no es necesario llevar un orden sistemático y estudia fenómenos naturales en relación con contextos específicos en la sociedad" (p. 34). En ese sentido, viene bien recordar a López (2002), quien opina lo siguiente: "Para realizar un trabajo de investigación, conviene llevar a cabo un desarrollo metódico, que permita la adecuada consecución de los objetivos propuestos, así como la formulación clara, concreta y precisa del problema" (p. 167).

Para Cortez, Escudero y Cajas (2017), sucede que: "La investigación documental, se sustenta en fuentes de índole documental, es decir, se apoya en la recopilación y análisis de documentos" (p. 20). Ahora bien, teniendo en cuenta lo descrito en el párrafo anterior, resulta preciso entender en qué consisten los estudios documentales, o bien, la fase documentaria en las investigaciones formales, y al mismo tiempo, reconocer en que se sustenta este tipo de investigaciones; para ello, es válido tener en cuenta lo que Cortez et al,. (2017), han referido: "Como una sub-clasificación de este tipo de investigación, se encuentra la investigación bibliográfica, misma que consiste en explorar, revisar y analizar libros, revistas científicas, publicaciones y demás textos escritos por la comunidad científica en formato impreso o material en línea. (p. 20) Con relación a los estudios documentales, Cortez et al,. (2017), han explicado lo siguiente:

La investigación documental es aquella estrategia orientada a revisar y reflexionar sistemáticamente las realidades teóricas de diferentes fuentes y campos de la ciencia, indagando e interpretando sus datos, valiéndose de métodos e instrumentos que ayudan a obtener resultados que pueden sustentar el desarrollo de la creación científica. (p. 20)

Así entonces, además de tener presente en qué consisten los estudios documentales, también conviene recordar que más allá de cualquier cosa, las labores investigativas atinentes a la documentación, comprenden también la revisión bibliográfica, necesaria en la fase 
indagatoria documentaria con aproximación a un fenómeno socio-antropológico, como es el caso del abordado por el estudio en cuestión. De la misma forma, vale acotar que como método, la hermenéutica-dialéctica, permite abordar de forma neurálgica los contenidos que reposan en cada una de las fuentes escritas, seleccionadas por los investigadores para completar la carga documental, misma que abarcó un periodo que fue desde el año 2002 hasta el 2021. De tal modo, conviene exponer de que trata el método aplicado en el presente estudio, para ello, se tomó en cuenta a Sandin (como se citó en Atencio, 2015), quien ha planteado que:

Existen diversas corrientes inmersas en las vertientes del interpretativismo, por lo que en los estudios documentales el método hermenéutico dialéctico, reconceptualizado no sólo como una herramienta para resolver los problemas de interpretación textual, sino como una fuente de reflexión sobre la naturaleza y el problema de la comprensión interpretativa en sí misma, se eleva como el más efectivo en este tipo de investigaciones. (p. 231)

Ahora bien, con atención a la técnica aplicada en este estudio, es fundamental dejar claro que los avances acá expuestos, se lograron a través de la documentación, técnica seleccionada por los investigadores para la auscultación de los documentos escogidos, que fungieron como fuentes del conocimiento necesario para la elaboración del presente escrito, relacionado a ello Aleixandre et al., (como se citó en Gómez, Navas, Aponte y Betancourt, 2014), han referido lo siguiente: "El trabajo de revisión bibliográfica, constituye una etapa fundamental de todo proyecto de investigación y debe garantizar la obtención de la información más relevante en el campo de estudio, de un universo de documentos que puede ser muy extenso" (p. 158).

Según Guevara (2016), resulta que: "Las técnicas son elementos clave en el desarrollo de la investigación porque permiten el acercamiento a la realidad documental y suponen una naturaleza epistemológica del objeto de estudio" (p. 177). Con atención a la técnica de revisión documental, también conocida como documentación, autores como Martín y Lafuente (2017), explican: "Este proceso también es conocido como búsqueda documental, revisión de antecedentes, investigación bibliográfica o documental" (p. 152). Es importante tener en cuenta que la misma consiste, según Rojas (2011), en lo siguiente: "Esta comprende una serie secuencial de procedimientos orientados a la aproximación, al procesamiento y recuperación de información contenida en documentos, independientemente del soporte documental en que se hallen" (p. 279).

Por otro lado, los investigadores seleccionaron como instrumentos investigativos a la matriz bibliográfica y a la matriz de análisis de contenido; respecto a la primera, autores como Gómez, Galeano y Jaramillo (2015), plantean lo siguiente: "La matriz bibliográfica comprende un instrumento diseñado en Excel, donde se hace un inventario de todos los textos que conformaron el universo y sobre el cual se aplicaron los filtros de selección" (p. 426). De la misma forma, es preciso acotar en que consiste la matriz de análisis de contenido; en opinión de Andréu (2002), sucede que: "Esta se basa en la lectura textual o visual, como instrumento de recogida de información, lectura que a diferencia de la lectura común, debe realizarse siguiendo el método científico, es decir, debe ser, sistemática, objetiva, replicable, valida" (p. 02). Desde su experiencia como investigadores, Gómez et al,. (2015), han reseñado lo siguiente: 
La matriz analítica de contenido comprende un instrumento diseñado en Excel donde se relacionaron los textos de la muestra, escritos en vertical, con las categorías de análisis, escritas en horizontal. De cada texto se extrajeron todos los párrafos o frases donde se desarrolló un tema relacionado con alguna de las categorías y se ubicó en la escuadra. También contó con la bibliografía y las observaciones de cada texto de una forma organizada que facilitó la lectura lineal y transversal. (p. 426)

Ahora bien, con relación a la matriz de análisis de contenido, en opinión de Díaz (2018), sucede que: "En ella la idea es desarrollar la perspectiva interpretativa de los textos, profundizando más allá de del contenido manifiesto, también al contexto y contenido latente desde donde se expresa el mensaje" (p. 126). Es preciso indicar que en este tipo de estudios, las unidades de análisis están conformadas por la batería archivos documentales, seleccionados en el momento heurístico, que hayan sido intervenidos por las técnicas e instrumentos escogidos; para luego confrontar, analizar e interpretar, los argumentos más relevantes en el posterior momento hermenéutico, donde fueron atendidas las categorías y subcategorías emergentes. Todos estos contenidos reposan en archivos de tipo digital, entre los que se cuentan documentos escritos, videos e imágenes fotográficas, además de otros.

De allí, que se haya elaborado la revisión organizada, de la batería documental seleccionada durante el momento heurístico, la cual estuvo conformada por un conglomerado de archivos documentales, que en su totalidad estuvo integrada por artículos científicos, tesis doctorales e incluso trabajados de grado, en ciencias sociales y humanas. Vale destacar que para lograr esta masa documentaria, fue preciso indagar en diferentes portales académicos y científicos de orden global, tales como: Redalyc, EBSCO, Science direct. En ello, se aplicaron como criterios de búsqueda: Musculación, Estética, Valores estéticos, Belleza blanca y Eurocentrismo, todo lo anterior, favoreció la obtención de hallazgos más precisos. Es importante recalcar que la muestra documental final del presente estudio, estuvo integrada por 87 fuentes, que finalmente fueron reducidas a 33 obras, las cuales están referenciadas al final del presente artículo.

\section{DISCUSIÓN}

\section{Belleza Blanca, colonización del pensamiento hispanoamericano aún en la contemporaneidad}

En los últimos años la sociedad hispana contemporánea, ha logrado hacerse un lugar preponderante, en el imaginario cultural del mundo occidental. Atrás han quedado aquellos días donde las personas con origen al sur del continente americano, representaban la minoría en algunos países del primer mundo como EE. UU., Canadá, España, Francia, Portugal, entre otros, en los que el número de hispanos se ha incrementado de forma dramática, como consecuencia al movimiento transcontinental hacia los Estados del norte, más aún en aquellos que conforman la Europa Meridional, sobre todo en España, donde comparten un mismo idioma. Al mismo tiempo, como una suerte de transculturación, quienes han migrado hacia estas lides, han hecho suyos algunos matices culturales, que distan mucho de los que les fueron brindados en sus países de origen, he allí donde surge la otredad cultural, sobre la que se cierne el discurso de este estudio. 
Del mismo modo, conviene decir qué, si bien es cierto que los movimientos migratorios dan lugar a un sinnúmero de fenómenos humanos, políticos, jurídicos, sociales y culturales, es también muy importante tener en cuenta el trasfondo de cada uno de estos, pues de allí, emergen los contenidos más preponderantes que permean a la temática principal de este estudio, el cual no es otro que el hombre hispano, como categoría investigativa, arquetipo social, esquema del comportamiento humano occidental, símbolo cultural e incluso figura ontológica. En ese sentido, resulta de interés para el desarrollo y prolongación del presente extenso... a manera de apéndice, como parte de los denominados Estudios del hombre, el abordaje al comportamiento manifiesto por estos, pero con la particularidad que se enfoca en sus aspiraciones estéticas de belleza, perfección y musculación.

Ahora bien, en el abordaje de los valores estéticos que comparten los hombres hispanos, resultó necesario enfocarse en aquello que desde su misma corporalidad, estos han manifestado alteridad. Exaltar tales o cuales son los estamentos estéticos que los varones hispanohablantes, acarician en su aspiración por concretar en su propio cuerpo, aquella personificación del modelo físico ideal, para lo cual es necesario profundizar, en la fuente de donde brota la imagen de la masculinidad perfecta, el cuerpo perfecto y hasta donde deben llegar para alcanzar tanta belleza. Es allí, donde logra comprenderse, que para los hispanos el cuerpo es el vehículo que les conduce hacia lo que desean ser. En opinión de Le Breton (como se citó en Ocampo, 2019a), sucede que: "El estudio social de lo corporal pone sobre la mesa el aspecto de que toda existencia es ante todo corporal" (p. 68); lo cual trae a colación la importancia de la imagen corporal. Según Arenas (2017), debe tenerse presente lo siguiente:

La corporalidad es pilar fundamental de la identidad de cada persona y por ende parte importante de cómo concibe y construye el contexto que habita. El cuerpo es discurso, manifestación clara, que opera a través de la acción de su movimiento. Y en ese movimiento realiza una relación con el espacio, en un diálogo con el contexto y una posibilidad de transformación constante. (p. 76)

Por ello, genera tanto interés comprender que hay más allá de lo que a los ojos se pueda reconocer, es decir, dar respuesta a diferentes interrogantes, entre las que se cuentan: ¿Qué les conduce a los varones hispanos cultivar su musculatura?, ¿Cuáles son sus expectativas? ¿Cuáles son sus experiencias?, ¿Por qué se puede ser bello solo con un cuerpo musculoso?, ¿A quién o que tratan de emular?, y así otros tantos cuestionamientos, dan origen al estudio de los valores estéticos, elementos dinamizadores de prácticas deportivas con pesas, como la musculación, halterofilia, físico constructivismo y el fitness en hombres hispanohablantes. En opinión de Mejía (2021), sucede que: "El culto al cuerpo se impone a favor de crear una cultura somática, en la cual el centro de atención gira alrededor de la presentación física y lo atractivo ante los demás, creando así contenido con base corporal" (p. 12).

En ese sentido, se destacan hechos donde la duda no encuentra lugar, pues resulta que la práctica con pesas, y el culto al cuerpo no es un fenómeno esnobista, ni menos emergente, desde hace siglos, el cuerpo masculino ha sido temática de interés para los pensadores, los artistas, los atletas e incluso para quienes viven su vida a través del físico y el deporte; más allá de ello, para los científicos en las ciencias del deporte y la tecnología del deporte. El cuerpo masculino, es el objeto de deseo de quienes viven del deporte, aquellos que comúnmente son conocidos como atletas profesionales, quienes detrás cuentan con un equipo multidisciplinario, para los 
que la carrera de este es su empresa. Cuando se habla del deporte, se está hablando del cuerpo físico del deportista, y todo lo que esto significa, entre lo que se destaca aquello que es capaz de lograr con su corporeidad.

Con referencia a lo expuesto en el párrafo anterior, surge gran interés por reconocer qué hay detrás de todo ello, por qué tanto empeño en alcanzar cierto estatus corporal e incrementar la capacidad física y muscular, hasta dónde son capaces de llegar los hombres hispanos por personificar el ideal de belleza masculina contemporánea, y más allá de ello ¿Cuál sería entonces ese modelo estético aspiracional?, ¿Cómo se debe lucir para lograr el reconocimiento social?, ¿De dónde surge aquella idea del cuerpo perfecto y como es que este arquetipo físico se ha vuelto tan procurado, al punto que los varones hispanos persiguen ser identificados con este?. Desde su lugar, Arenas (2017), explica que: "La identidad corporal de los sujetos, a partir de cómo son y cómo se mueven, les permite reconocer cómo son en sociedad, cómo se mueven y habitan en un contexto particular" (p. 77). Con relación a ello, Cortazar (2009), ha expuesto lo siguiente:

Entre los adeptos de esta nueva religión del cuerpo se tiene la auto-percepción de ser un hombre de acero. Imaginario alimentado en parte por las estrellas de cine, televisión y comic, los superhéroes, de cuerpos hipertrofiados, desde el mítico Charles Atlas en la década de los años veinte del siglo pasado, hasta los recientes Arnold Schwarzenegger y Sylvester Stallone. (p. 03).

Así entonces, puede entenderse que esta aspiración corporal, este ideal de belleza vigoréxica, no surge en momentos de época masculina, no, es un constructo cultural, que desde hace más de treinta años se ha ido perfeccionando, estilizando, alimentando en el imaginario occidental por el cine, la televisión, la publicidad y el mercadeo a través de los modelos sociales, que las luminarias de estas industrias proponen con su apariencia física. De allí, partieron, Flórez y Giraldo (2013), quienes expusieron lo siguiente: "El Cuerpo perfecto ha sido mostrado a través de la historia por los medios de comunicación, ha cambiado y ha sido objeto de deseo, razón para que las personas consuman todo aquello relacionado con la belleza física" (p. 03).

Entre tanto, queda claro que la imagen aspiracional, que responde a los anteriores cuestionamientos, está representada por el hombre alto, fornido, atlético y por sobre todo blanco y que en la cultura popular contemporánea, ha sido encarnada desde el séptimo arte tanto por Arnold Schwarzenegger [Thal, Austria, 1947] como por Sylvester Stallone [Nueva York, Estados Unidos, 1946], -quienes fueron referidos en líneas anteriores-, dos actores norteamericanos de origen europeo, propuestos por la industria del cine hollywoodense desde mediados de los años 80’s, como el varón ideal en el mundo occidental, desde hace más de treinta años, y de hecho aún antes, entre los años 40`s, 50`s, 60`s, y 70’s los míticos y heroicos roles masculinos protagónicos, eran personificados exclusivamente por actores caucásicos, preferiblemente de origen estadounidense y británico, entre los que podría contarse a Clark Gable [Ohio, Estados Unidos - California, Estados Unidos, 1960], Charlton Heston [Illinois, Estados Unidos, 1923 - California, Estados Unidos, 2008], Marlon Brando [Nebraska, Estados Unidos, 1924 - California, Estados Unidos, 2004], Rock Hudson [Illinois, Estados Unidos, 1925 - California, Estados Unidos, 1985], George Peppard [Michigan, Estados Unidos, 1928 California, Estados Unidos, 1994], Rod Taylor [Lidcombe, Australia, 1930 - California, Estados Unidos, 2015], por mencionar algunos; solo que en este extenso no se hace hincapié en 
ello, por cuanto a partir de 1980 fue que se exacerbó la musculatura y apariencia física masculina en los varones blancos, que con su talento interpretativo iluminaron la gran pantalla; respecto a ello, los investigadores Buitrago et al,. (2021), han explicado que: "Hollywood es la principal factoría de estereotipos de consumo masivo, por proponerse en erigir, instaurar, sostener, capitalizar y explotar los modelos masculinos estéticamente maximizados, donde el macho fornido, robusto, alto, blanco, velludo, dotado, se ha presentado como el ideal masculino" (p. 60).

Sin embargo, cabe acotar qué aun cuando es muy cierto, que desde la primera década de los años 2000, la cinematografía occidental contemporánea, está llena de actores de color con las mismas concepciones estéticas, entre los que podría contarse a Cress Williams [Heidelberg, Alemania, 1970], Michael Clarke Duncan [Illinois, Estados Unidos, 1957], Ving Rhames [Nueva York, Estados Unidos, 1959], Idris Elba [Hackney, Londres, Reino Unido, 1972], Dwayne Johnson [California, Estados Unidos, 1972], Wesley Snipes [Florida, Estados Unidos, 1962], Will Smith [Pensilvania, Estados Unidos, 1968], Samuel L. Jackson [Washington D. C., Estados Unidos, 1948], Cuba Gooding Jr. [Nueva York, Estados Unidos, 1968], Terrence Howard [Illinois, Estados Unidos, 1962], Don Cheadle [Misuri, Estados Unidos, 1964]; no fue sino hasta el año 2018 que el actor Chadwick Aaron Boseman [1976, Anderson, Carolina del Sur, Estados Unidos - 2020, Los Ángeles, California, 1946] encarnara al mítico personaje Pantera Negra, en la exitosa película que lleva el mismo nombre, marcando un hito en la meca del cine ${ }^{1}$; no sólo porque resultó ser una de las obras cinematográficas, con mayor recaudación de taquilla en los últimos 10 años o por ser la primera película de superhéroes en recibir una nominación al Óscar como Mejor película, o ser la primera película en el Universo cinematográfico de Marvel en ganar un Premio Óscar, así como muchos otros reconocimientos; sino porque fue la primera vez que un actor afroamericano, interpretase el rol principal en una película de superhéroes estadounidense ${ }^{2}$, enviando así un claro mensaje de inclusión, cuestión que recibió cualquier clase de señalamiento, por marcar un precedente real y contundente, en contra de la exclusión y discriminación por la que se había criticado a Hollywood durante tantos años ${ }^{3}$.

Del mismo modo, ha ocurrido con la adjudicación de personajes principales, en manos de intérpretes con origen latinoamericano, pues se ha observado que en el reparto de actores en una cinta cinematográfica de héroes estadounidense, muy pocas veces se ha otorgado roles destacados y menos aún principales a talentos hispanoamericanos. Según Buitrago et al,.

\footnotetext{
${ }^{1}$ Meca del Cine, es una de las formas más populares con la que suele referirse a Hollywood, un distrito de la ciudad de Los Ángeles, en la costa Oeste de Estados Unidos, donde desde 1911 se agrupan los estudios de cine más poderosos del mundo y que han producido gran parte de la cinematografía más comentada, reconocida, cotizada, premiada. Ese tipo de obra cinematográfica que cala en el imaginario social contemporáneo a nivel global, logrando alcanzar el estatus de película de culto.

${ }^{2}$ Black Panther [2018] es una cinta cinematográfica de superhéroes estadounidense, cuyo impacto cultural ha resultado ser inconmensurablemente significativo, para los afroamericanos en los Estados Unidos y los afrodescendientes a nivel global; pues la película presenta en sus contenidos un retrato de inclusión y positividad, para un grupo de personas que muy pocas veces, son presentadas como el centro de atención en las películas hollywoodenses. Todo lo cual ha fortalecido la identidad afrodescendiente, reduciendo así la probabilidad de internalizar estereotipos negativos sobre el grupo étnico propio. — Erlanger Turner, asistente profesor de Psicología en la Universidad de Houston-Downtown, Estados Unidos de América. https://www.houstonchronicle.com/local/gray-matters/article/black-panther-racial-and-ethnic-socialization-12741221.php

${ }^{3}$ En las últimas décadas la cinematografía hollywoodense ha sido calificada como racista, generando un tsunami de opiniones que han dejado en entredicho la ética de los estudios de cine estadounidense. https://www.google.com/amp/s/www.revistavanityfair.es/la-revista/articulos/el-primero-en-morir-ya-no-es-elnegro/46270/amp
} 
(2021), sucede que: "Hollywood ha instado a hombres y mujeres por igual a procurar al ideal de belleza blanca, en un sentido erótico, estético o social" (p. 60); son incontables las obras cinematográficas donde el héroe, el protagonista, el galán, el príncipe, el magnate, el político, el líder, el atleta, es personificado por algún actor de nacionalidad estadounidense o de algún país de Europa e incluso actores que aún nacidos en Estados Unidos son de origen europeo, "Obras donde los roles principales son encarnados por actores, dotados de atributos físicos recargados de testosterona y hormona del crecimiento" (Buitrago et al,. 2021, p. 60).

Igualmente, cabe recalcar que así como hace tres décadas se hizo apología al físico nutrido de hombres blancos como Arnold Schwarzenegger y Sylvester Stallone, igualmente en los últimos años estos roles han sido otorgados a actores y luminarias del séptimo arte, tales como: Henry Cavill [Saint Helier, Jersey, 1983], Armie Hammer [California, Estados Unidos, 1986], Wyatt Russell [California, Estados Unidos, 1986], Ben Barnes [Londres, Inglaterra, Reino Unido, 1981], Chris Evans [Massachusetts, Estados Unidos, 1981], Sebastian Stan [Constanza, Rumanía, 1982], Jon Hamm [Misuri, Estados Unidos, 1971], Zachary Levi [Luisiana, Estados Unidos, 1981], Tom Holland [Surrey, Inglaterra, Reino Unido, 1996],... quienes interpretan seres mitológicos en el universo de la animación; elevando así de forma constante la superioridad del hombre blanco, fornido, privilegiado, admirado y reconocido, dando lugar a alguna forma de fetichización de este fenotipo masculino; todo lo cual resulta demasiado cuando al momento de comparar, solo hubo un actor de color encarnando el rol más importante, en una película de superhéroes estadounidense ${ }^{4}$ producida por Marvel Studios, que desde el 2008 ha estrenado 25 películas y cuatro series de televisión.

A tenor de lo expuesto, se reconoce que la industria cultural en general, rinde gran apología a la belleza blanca masculina, elevándole como el arquetipo ideal, el modelo físico aspiracional en occidente, con mayor reconocimiento y aceptación entre las masas, dando lugar a una de las tantas aristas, que se desprenden de teorías propuestas desde hace varias décadas, donde se exponen los privilegios del hombre con base al color su de piel, siempre y cuando se trate de un varón blanco o caucásico. Respeto a ello, algunos autores como Balcazar, Berardi y Taylor (2011), han planteado lo siguiente: "Las descripciones fenomenológicas de autoras como Peggy McIntosh, tras sus hallazgos entre los años 1988, 1992, 2004, 2019; son comúnmente aceptadas en los círculos académicos y citadas en copiosas publicaciones, que describen las bases conceptuales del privilegio de los blancos" (p. 86).

Con relación a lo anterior, Mejía (2021), expresa lo siguiente: "El estereotipo de belleza masculina en medios de comunicación masiva, expone cuerpos musculosos en imágenes explicitas, mostrando su figura e intervención como la de un salvador o superhéroe, dando mayor fuerza a la idea de conseguir una musculatura superior" (p. 44). Así entonces, se genera un ideal de belleza masculina apoyado en la piel blanca, musculatura vigorosa y estatura física superior; exacerbando así las características masculinas al máximo, ante lo cual, es válido recordar a Morales (2020), quien sostiene que: "La construcción social androcéntrica del cuerpo legitima la dominación masculina. En ello, el cuerpo del varón y su lenguaje son dos factores que influyen en la experiencia que tendrá cada persona, en el entorno social de manera colectiva

\footnotetext{
${ }^{4}$ Black Panther [cinta cinematográfica] [2018]. Dirigida por Ryan Coogler, producida por Kevin Feige, Fox Searchlight Pictures \& Marvel Studios, distribuida por Walt Disney Studios Motion Pictures, Estados Unidos. $\underline{\text { https://m.imdb.com/title/tt1825683/?ref_=fn_al_tt_0 }}$
} 
e individual. (p. 06). A tenor de lo anterior, en el contexto expuesto por los últimos párrafos, pareciera reconocerse al hombre blanco como el fenotipo superior, el héroe, el protagonista, el salvador de los demás hombres y mujeres, para el que todo debe estar disponible y al alcance.

Así entonces, en opinión de Fanjul (como se citó en Méndez y Rico, 2019), sucede lo siguiente: "Los modelos estéticos que se difunden a través de la publicidad y los medios, se perfilan como un factor predisponente y mantenedor de las patologías vinculadas con cuadros obsesivos por el aspecto físico" (p. 174), robusteciendo la figura del varón blanco y fornido como símbolo de masculinidad ideal. Por su parte Méndez y Rico (2019), han apuntado que: "Los estereotipos, clases sociales, grupos sociales, idealizaciones y preferencias estéticas, uso del género, la discriminación y el racismo, giran en torno al cuerpo y su forma, otorgando mayor relevancia al hombre por ser blanco" (p. 174), En lo que a ello respecta, Balcazar, Berardi y Taylor (2011), han planteado:

En general, el privilegio de los blancos se define como la experiencia de ventajas que los blancos experimentan basándose exclusivamente en sus características físicas y sociales. La primera característica es que dichas ventajas son adquiridas sin esfuerzo. La segunda característica es que dichas ventajas no son el resultado de talentos particulares. Tercero, las ventajas tampoco son comunes ni universales. Cuarto, están asociadas con las condiciones o estatus social y posición de poder de los individuos; y quinto, aquellos que gozan de dicho privilegios no son conscientes de los mismos. (p. 86)

Así pues, se plantea que entre los valores estéticos del hombre hispano contemporáneo, se eleva el de la belleza blanca, impuesta más recientemente por la industria cultural con origen en Estados Unidos; no obstante vale reconocer que la estética como rama de la filosofía, permite a los estudiosos del comportamiento humano, comprender tales o cuales son los elementos que el hombre racionalista reconoce como de su mayor interés. Es decir que para lograr deconstruir su alteridad, el varón hispanohablante de forma innata procura su propio modelo a seguir, y echa mano de aquello que le rodea de forma constante, como lo son los contenidos visuales que ofrece el séptimo arte, todo lo cual conforma el objeto de estudio, para quienes han generado teorizar alrededor de la belleza blanca, como valor estético adoptado por los varones hispanos. Ahora bien, todo este interés por comprender en trasfondo de dicho fenómeno, emerge entre los investigadores a razón de los contenidos expuestos por Balcazar, Berardi y Taylor (2011), quienes han dejado claro lo siguiente: "Los trabajos investigativos que procuran estudiar el comportamiento social, orientado a la maximización del hombre blanco, provienen de un área multidisciplinaria de estudios en la ciencias sociales de los Estados Unidos llamada whiteness Studies" (p. 86). En ese sentido, cabe preguntar: ¿Por qué recurrir a la estética para descifrar el origen de estos arquetipos?

En ese orden de ideas, es válido reconocer o mejor dicho retrotraer que durante siglos se generó en los varones hispanos, una suerte de paradigma cultural donde aquellos que son de piel blanca, suelen ser más y mejor aceptados que otros hombres de color o de características indígenas, todo lo cual se ha filtrado en cualquier evento sociocultural de interés, aún en la contemporaneidad, y Balcazar, Berardi y Taylor (2011), se permiten explicarlo así: "Desde el momento en que los hombres blancos pisaron suelo americano, vieron con desprecio a los nativos, quienes heredaron un complejo de inferioridad, pues lo autóctono y lo indígena, siempre fue considerado por los colonizadores como inferiores a lo europeo" (p. 91), por su 
parte, Ortiz (2013), lo resume de esta forma: "El modelo hegemónico de belleza, es el modelo estético blanco" (p. 178), refiriendo con esto que a partir de la belleza blanca, es que se evalúa cualquier otro fenotipo, independientemente del grupo etario al que este pertenezca.

De conformidad con lo dispuesto, resulta de interés recordar lo que investigadoras como Peralta y Hernández (2021), plantean: "El ser humano, parte de arquetipos culturales que le son propios y ejerce un empoderamiento de principios y valores, condicionados por su conducta en cierta medida; los cuales pone de manifiesto en sus relaciones interpersonales" (p. 05), es decir, que todos estos principios culturales o valores estéticos, dictan los esquemas del comportamiento humano en sociedad, replicándose así en el comportamiento social y masivo de los grupos humanos, todos estos procesos también encuentran lugar en el interés de los estudios del hombre, más aún cuando la sociedad occidental ostenta un origen patriarcal, heteronormativo y falocentrista, donde la figura del varón blanco es el pilar fundamental y el paradigma de mayor peso.

A tenor de lo anterior, conviene tener en cuenta aquello sobre lo cual coincide Schongut (2012), quien explica lo siguiente: "Los estudios de masculinidad, si bien son más recientes que los estudios sobre la mujer, cuentan con un recorrido y una historia importante, lo que se traduce en la aparición y uso de nociones que son fundamentales para su comprensión" (p. 44), o sea, que en el desarrollo y prolongación de los estudios del hombre y su masculinidad, también se reconocen acervos, en los hallazgos generados por los estudios en las ciencias sociales denominados whiteness Studies, así como otras tantas investigaciones sobre la belleza blanca, la supremacía blanca con origen en Europa, donde la superioridad del hombre blanco ha sido reconocida desde un enfoque científico, en el abordaje de eventos históricos como la Segunda Guerra Mundial (1939 - 1945) y el consecuente holocausto; respecto a esto último, continúa Schongut (2012), exponiendo que:

Esta lógica se repite entre grupos de masculinidades hegemónicos y subordinados. Al recordar que el género está cruzado por otras construcciones socio-históricas, como son la raza o la clase social, puede muy bien recordarse historias sumamente vergonzosas, como la esclavitud de la raza negra o los campos de concentración de la Alemania Nazi, donde la hegemonía solo podía ser ejercida por el hombre ario heterosexual, mientras que los judíos, gitanos y homosexuales eran enviados a los campos de exterminio, para ejercer trabajos forzosos o finalmente ser ejecutados. (p. 54)

Al respecto, Balcazar, Berardi y Taylor (2011), han planteado que: "En hispanoamérica, este constructo se experimenta en forma más directa y abierta, con expectativas más claras de sumisión de parte de las personas de color y directamente asociado a diferencias de clase" ( $p$. 103). Así pues, en la cultura hispana el modelo masculino ideal, se parece más al hombre nórdico que al indígena o al afrodescendiente, tras varias décadas de consumo de estereotipos generados por la industria del entretenimiento, todo lo cual se ve reflejado en aquel masivo interés de los varones contemporáneos, por lograr un cuerpo vigoroso, musculoso y blanco. Por su parte, Mejía (2021), ha indicado que: "En la sociedad actual el culto al cuerpo se ha convertido en una obsesión. Obtener y lucir un cuerpo perfecto es el gran reto a alcanzar, demostrando hasta qué extremo se puede llegar para alcanzar los patrones de belleza impuestos" (p. 12). 
Sexualización del cuerpo masculino, una respuesta a la musculación en el contexto hispano contemporáneo

De conformidad con lo anterior, puede reconocerse como en los últimos años se ha erotizado al cuerpo masculino, convirtiéndole en objeto de deseo y de consumo masivo, siempre y cuando se presente como un varón blanco, musculoso, alto y vigoroso, es decir, cada vez que este exponga ciertas características físicas. Por ello, en el cine comercial y numerosas campañas publicitarias, se muestra al hombre como un ser fuerte, imponente, atractivo, blanco y fornido o atlético, en ello coincide Morales (2020), quien sostiene lo siguiente: "En el cine X, las acciones de los hombres siempre tienden a ser exacerbadas, imponentes y fuertes. Mediante este comportamiento se reafirma las relaciones de poder que existen entre el hombre blanco y la mujer latinoamericana, afrodescendiente o del sudeste asiático" (p. 04). Así pues, se expone al hombre como una figura superior en un sentido físico, sí, pero también simbólico, de allí que adquiera tanta relevancia el estudio del comportamiento masculino en la industria cultural. Al respecto, la misma autora e investigadora en ciencias sociales, Morales (2020), ha referido lo siguiente:

La lógica de dominación, ha sido una ideología presentada arbitrariamente como inherente a la naturaleza humana. Se normalizan las relaciones de dominación, basándose principalmente a las características corporales de las personas, a partir de la diferenciación de los órganos sexuales. Es así, que se justifica de manera objetiva y biológica los roles sociales y cognitivos de los hombres y las mujeres, siempre posicionando al hombre blanco por encima de la mujer, sin importar a que etnia esta pertenezca. (p. 05)

Ahora bien, al abordar el comportamiento masculino en la industria cultural contemporánea, pueden reconocerse diferentes arquetipos, donde el hombre blanco y fuerte, dotado, se destaca por encima de otros, incluso, existe una carga multitudinaria de obras generadas por la industria del entretenimiento, donde se eleva al varón blanco por encima del hombre afrodescendiente e indígena, y más aún por encima de la mujer, sobre todo si se trata de una mujer de color. Con relación a esto Guevara (2008), ha referido que: "Los estudios en torno al tema de la masculinidad han logrado avanzar, ofreciendo aportes significativos en diferentes campos de conocimiento, que utilizan la perspectiva de género para fundamentar sus propuestas" (p. 76). Por su parte, autores como Morales (2020), han dejado claro lo siguiente:

No se cuenta con un dato exacto de cuando empezó esta jerarquía de géneros, pero ha estado presente desde tiempos arcaicos. En la época aristócrata se tenía una gran devoción a la belleza masculina. [...] para aquellos el cuerpo era ante todo un cuerpo estético (aiesthesis), esto era, un cuerpo bello, bellum. El cuerpo bello es un cuerpo de hombre. (p. 06)

Por ello, aunque se trate de un fenómeno que pase desapercibido para muchos, de forma implícita se sigue presentando esta supremacía del hombre blanco, en casi cualquier obra que se desprenda de la industria cultural, y el mejor ejemplo de ello es el séptimo arte, donde independientemente del género al que cada película pertenezca: comedia, drama, romance, 
acción, ficción, suspenso, misterio, terror, gore, slasher, giallo, X, continua exponiéndose una raíz común en cada metraje, donde todo parece girar alrededor del varón caucásico; secuencias en las que casi cualquier cosa se expone a favor del hombre blanco, sobre todo si se trata de la mujer, donde esta al final de la trama se rinde ante su superioridad, fuerza, valentía, más aún si se trata de una mujer joven negra, blanca, latinoamericana o del sudeste asiático, filtrando y al mismo tiempo normalizando, naturalizado e incluso romantizando así... el mensaje de sumisión de la mujer a los pies del hombre blanco.

Respecto a ello, Ortiz (2013), sostiene lo siguiente: “A pesar que el modelo estético blanco, sea solo uno de los diversos estereotipos disponibles en la sociedad, es a partir de este que se establece una jerarquía y se evalúan los demás" (p. 177). Lo anterior, se ve replicado en diferentes estrategias publicitarias con origen la cultura occidental, influenciada por los esquemas esteticistas, establecidos por los generadores de contenidos desde Estados Unidos; todo lo cual Cortazar (2009), se permite explicarlo así: "El cine, la publicidad y los medios de comunicación proyectan modelos físicos específicos, como ejemplo para los demás, generando así una eugénesis social, esta eugenesia social, hace referencia a la limpieza o purificación de las etnias en hispanoamérica" (p. 10), es decir, que el blanqueamiento de la piel en la sociedad hispana, se percibe como una suerte de purificación racial, lo que desde el coloquio autóctono se describiría como mejorar la raza.

Para Hunter (como se citó en Ortiz, 2013), sucede que: "La mercadotecnia masiva de imágenes contemporáneas sobre la belleza blanca, tienen su origen en las viejas ideologías coloniales, que impusieron su cultura y estéticas corporales en detrimento del resto" (p. 186). Del mismo modo, se han ido reproduciendo los modelos estéticos, generando así el sostenimiento de los valores estéticos influenciados por el pensamiento eurocentrista, es decir que como una de tantas aristas, la belleza blanca y su idealización, es una muestra más del impacto que causó, en el imaginario social hispanoamericano la colonización del pensamiento; dando lugar así al interés de los varones hispanos aún en la contemporaneidad... por ajustar su identidad a los esquemas del norte. Respecto a ello, Ocampo (2019a), ha expuesto lo siguiente: "La sociedad de consumo, fomenta en los sujetos nuevas formas para construir identidades" (p. 66), de esta manera se fueron prolongando los valores eurocéntricos.

En ese sentido, conviene recordar que los ideales de belleza masculina en la sociedad hispana contemporánea, aun en los últimos años, continúan relegando y renegando las características fenotípicas, genéticas de los afrodescendientes, indígenas o nativos, decantándose por el encanto de la piel lechosa, al que se le ha acostumbrado recibir, como paradigma estético de forma masiva durante siglos, aún en los últimos años ...es así como: "El modelo de belleza hegemónica o dominante, ha sido impuesto por la cultura occidental y alude en la actualidad al cuerpo sano, estilizado, joven y sobre todo blanco" Schuman (como se citó en Ortiz 2013, p. 177). Por ello, se puede reconocer que: "La cuestión de la belleza blanca es muy importante en las sociedades occidentales, porque lo blanco se asocia con el prestigio social, dentro de las jerarquías raciales existentes" (Ortiz 2013, p. 181).

Ahora bien, desde su experiencia la autora Morales (2020), ha expuesto lo siguiente: "En el cine X comercial, se reconocen elementos estéticos recurrentes entre los varones, estos suelen ser fuertes, de grandes estaturas y vigorosos músculos; estereotipando así al hombre corpulento y más grande que la mujer, imponiendo su masculinidad en todo momento” (p. 18). De allí, que 
surjan los nuevos modelos de masculinidad como el spornosexual, referido en algunos párrafos anteriores, donde se encarnan características físicas masculinas maximizadas, generando así en los varones hispanos gran interés por lograr ajustar su cuerpo, a un estereotipo físico fundamentado en una musculatura exacerbada. De acuerdo con ello, Mejía (2021), ha explicado que: "En la sociedad actual el culto al cuerpo se ha convertido en una obsesión. Obtener y lucir un cuerpo perfecto es el gran reto a alcanzar, demostrando hasta qué extremo se puede llegar para alcanzar los patrones de belleza impuestos" (p. 12).

Sin embargo, para lograr comprender todos estos procesos, es necesario profundizar en ello, y al mismo tiempo, vincularles con otros tantos fenómenos, que le otorguen el humanismo suficiente que les deslastre de la frivolidad, que para muchos pudieran caracterizar a estos eventos sociales, en pos de auscultarles en un sentido fundamentalmente científico. Es decir, para lograr exponer de qué forma se relacionan los valores estéticos, con la musculación y el ideal de belleza masculina descrita en este extenso, conviene describir los vínculos entre esta práctica deportiva, y los modelos estéticos procurados por quienes ejecutan la actividad física con pesas. Aún así, no es una cuestión fácil de elaborar, pues estas categorías no son comúnmente vinculadas entre sí en un mismo estudio, como en este caso. En ese orden, los autores Flórez y Giraldo (2013), han explicado que:

No existen muchas investigaciones psicológicas relacionadas con el grupo social de fisicoculturistas, es un tema aún poco explorado desde la perspectiva cualitativa y desde el punto de vista subjetivo; por esto se considera importante comenzar abrir otros campos de investigación con otro tipo de población, donde el cuerpo si bien sigue cánones de belleza, tiene otro tipo de interpretación y construcción de la realidad. (p. 04).

Por ello, para entender de dónde resurgen estos modelos, resultó necesario desarrollar la idea de los valores estéticos y la belleza blanca, pues en opinión de los investigadores, son el origen del modelo masculino aspiracional, al que apuntan los hombres hispanos que ejercitan con pesas, en las distintas disciplinas como la halterofilia, el fisicoculturismo, la musculación, el fisicoconstructivismo... anhelando perfeccionar con el entrenamiento y las modalidades de carga y descarga un cuerpo vigoroso, robusto, enorme, como el que presentan las obras del séptimo arte, referidas anteriormente, al que ellos desean ajustarse. De ahí que Mejía (2021), haya expresado lo siguiente: "Se vive en una realidad social donde se valoriza la fisonomía de las personas, basados en un estereotipo marcado por la sociedad, siendo estos irreales e insalubres, difundidos por los distintos medios de comunicación" (p. 03).

Con relación a todo lo anterior, adquiere relevancia lo expuesto por Ocampo (2019), quien refiere que: "La aparición del cuidado estético del cuerpo en los hombres, en determinados contextos socioculturales, no necesariamente pondría en duda su masculinidad, y hasta incluso puede ser entendido como nueva exigencia del ser hombre, proporcionando otras características al modelo estético masculino" (p. 131). En la cultura hispana contemporánea, se acepta de mejor forma a un varón blanco o con la piel más clara de lo que comúnmente se esté acostumbrado a ver, es una forma de legado cultural, heredado desde la colonización europea por más de cuatrocientos años, y aún ahora en los últimos treinta años ello ha sido redituado por la industria cultural con origen en los países del norte, como EUA, España, Francia, Canadá, Inglaterra, a través de los estereotipos masculinos a los que se les rinde culto, y que estos 
manejan e imponen sin el menor disimulo. Con relación a ello, Mejía (2021), ha expuesto lo siguiente:

El culto al cuerpo se define como las ideas, pensamientos y estereotipos que los individuos poseen y se idealizan acerca del cuerpo perfecto, creando cánones sociales y estéticos basados en lucir el cuerpo perfecto como comúnmente lo llamamos, demostrando de esta manera que la opinión de la sociedad, sí influye la formación y constricción de la personalidad y de la apariencia física de los individuos, a través de la creación de estereotipos basados en lo que imaginariamente es perfecto. (p. 45)

Entre tanto, a cada estereotipo masculino sea blanco o no, se le adjudica cierto patrón comportamental deseado. Así pues, en el caso del varón blanco, se espera manifieste un comportamiento heroico, vigoroso, dominante, y al mismo tiempo exhiba una constitución física nutrida, robusta y con gran estatura, tal cual como en muchas oportunidades ha sido retratado el modelo masculino en la industria cultural nórdica, todo lo cual arrastra un conglomerado de fenómenos, que trascienden el halo de las ciencias humanas y sociales. Es así, como adquiere importancia y relevancia aquello que Buitrago, Gutiérrez y Romero (2021), han afirmado: "Según el rol que cada persona haya preferido o se haya visto obligada a ejercer en sociedad, inevitablemente le vinculará a un conglomerado e infinidad de procesos con alcance supracultural” (p. 27). En lo que a ello respecta, Mejía (2021), ha planteado lo siguiente:

Hoy por hoy la creación de la imagen corporal, no solamente se trata de imponer los gustos personales, sino más bien por la imposición mediática de los distintos actores sociales, que presentan la imagen idealizada del cuerpo perfecto, a través de la creación de estereotipos del cuerpo ideal, con un enfoque en las necesidades que implantan las industrias culturales. (p. 12)

En tal sentido, pudiera tenerse en cuenta a Vilas (2019), quien apunta lo siguiente: "Existe una estrecha vinculación entre la imagen corporal individual y la compartida socialmente por un grupo determinado, las cuales se encuentran en constante intercambio" (p. 70). En consecuencia, las aspiraciones que los hombres hispanos comparten con relación a la belleza masculina, tienen su origen en sus valores estéticos comunes, heredados de sus antepasados con anclaje al pensamiento eurocentrista, y que en los últimos treinta años recibieron el impacto cultural de los países nórdicos. Así pues, se genera una suerte de identidad colectiva, donde aun cuando no todos los hispanos cuenten con el fenotipo caucásico, si, muchos procuran acoplarse a aquella estructura física vigorosa, que ha sido propuesta desde la industria cultural y audiovisual por Norteamérica y Europa. En opinión de Flórez y Giraldo (2013), sucede que: "Determinados grupos sociales forman comportamientos y conocimientos particulares frente a cómo construir su corporalidad, lo cual no solo les permite compartir una realidad sino también crear una identidad" (p. 04)

Ahora bien, ante lo descrito a esta altura del extenso, conviene tener en cuenta la postura de Flórez y Giraldo (2013), quienes han explicado lo siguiente: "El consumismo y la preocupación por verse bien, han traído consigo la proliferación de lugares especializados para ejercitar el cuerpo, como gimnasios y centros de acondicionamiento físico, donde el cuerpo se posiciona como un aspecto importante dentro de estos contextos" (p. 02). Lo anterior, deja en evidencia el interés con que otros investigadores han observado, el comportamiento de quienes se sienten atraídos por cultivar su físico y mejorar su estructura muscular, adquiriendo una 
mejor figura, aunado todo esto al impacto en la cultura, que estas prácticas deportivas con pesas han generado, modificando, alterando, diversificando la rutina diaria de muchos hombres al sur del continente americano, cuestión que no es ninguna novedad. Al respecto, Le Breton (como se citó en Cortazar, 2009), ha explicado lo siguiente:

Como tendencia el físico-culturismo se desarrolla a partir de los años 50's en Estados Unidos, pero no es sino hasta los años 70's y 80's que adquiere verdadera fuerza en los países del tercer mundo, a través de la moda de los gimnasios, como lugares consagrados al cultivo del cuerpo y su apariencia. Más aún, es a finales del siglo XIX y principios del XX que se puede datar el surgimiento de este nuevo imaginario sobre la fortaleza física, con los circos itinerantes de entonces, donde junto a otros prodigios y maravillas se exhibía a la mujer barbuda, al hombre bala y, por supuesto, al hombre más fuerte del mundo, generalmente vestido con una piel de animal salvaje a la manera de un cavernícola, levantando unas enormes pesas y mostrando una expresión fiera. (p. 03)

Así entonces, cuando se auscultan los contenidos relativos al entrenamiento con pesas, el culto al cuerpo y la concepción de la belleza masculina entre quienes practican la musculación, conviene tener en cuenta por aquello que deben atravesar para alcanzar el físico deseado, $e l$ cuerpo perfecto, al que se hizo referencia durante todo el extenso, y sin ánimos de rendirle pleitesía a ello, sería preciso acotar que no es cuestión fácil, ya que muchos atletas o deportistas adeptos a la musculación y el fisicoconstructivismo, exponen su seguridad física e incluso su vida, a los fines de encarnar frente al espejo aquello que tanto aspiran. En opinión Castro, Molero, Cachón y Zagalaz (2014), es importante resaltar lo siguiente: "Para lograr un buen resultado, los fisicoculturistas llevan a cabo una serie de acciones, que consisten en largos días de entrenamiento con pesas, dietas restrictivas ricas en proteínas y carbohidratos, uso de ayudas ergogénicas permitidas y, en ocasiones, también no consentidas" (p. 296).

A tenor de lo anterior, es fundamental tener en cuenta y reconocer que la transformación del cuerpo humano, no es un proceso fácil, económico, ni premuroso, aunque sin muy dúctil, y por lo general comienza a gestarse desde la psique, la encarnación del cuerpo ideal empieza desde el pensamiento y la intención del deportista por adquirir un nivel de masa muscular superior, mejorar su rendimiento físico y acrecentar su fuerza, todo lo cual configura una multiplicidad de procesos, que de forma sistemática concretan el resultado aspirado. Desde su experiencia, Cortazar (2009), sostiene lo siguiente: "Es la trasformación del cuerpo en una máquina donde la identidad es trabajada a través de los músculos, vistos como un producto controlable y el gimnasio representa el lugar donde el cuerpo es castigado para lograr su perfección" (p. 02). Entre estas disciplinas se cuentan: halterofilia, musculación, fitness, fisicoculturismo y fisicoconstructivismo. Al respecto Durán y Torres (2021), han expuesto que:

La Halterofilia es un deporte olímpico de Levantamiento de Pesas, se deriva de dos palabras haltera y filia; la haltera es una barra metálica con una bola o con discos en cada extremo y filia representa simpatía o afición por una determinada persona o cosa, es decir, significa afición por el levantamiento de pesas. (p. 189)

Ahora bien, conviene recordar que el ejercicio físico como filosofía de vida comprende un gran compromiso, más aún cuando se trata de llevarlo al máximo nivel, y que esto se vea reflejado en el aspecto físico y las formas corporales del deportista, cabe señalar que en la 
mayoría de los casos, quienes entrenan con levantamiento de pesas, no necesariamente persiguen equilibrar salud, físico y vida; pues su meta máxima suele ser desarrollar una estructura muscular vigorosa, marcada, que incluso supere los estándares de la normalidad. Al respecto, Cortazar (2009), sostiene que: "El entrenamiento es una práctica ascética, de renuncia a los placeres como vía de perfección, de una existencia dedicada a los músculos y a la apariencia. En el caso de los hombres es una demostración de masculinidad” (p. 02).

Desde su experiencia, Flórez y Giraldo (2013), han explicado que: "El fisicoculturismo, es una manera de representar y cultivar el cuerpo, cómo a través de rutinas, alimentación adecuada y en ocasiones esteroides o anabólicos, la persona logra construir lo que la sociedad considera un cuerpo perfecto" (p. 03). Lo más interesante de estas prácticas deportivas, es que ciertamente resultan seductoras para los atletas, más aún para aquellos que con la aspiración de modelar su cuerpo, se toman en serio este tipo de entrenamientos a manera de circuitos, o como rutina diaria. De hecho, algunos en su interés superior por lograr marcarse, suelen entrenar tanto de día como de noche, en una misma jornada diaria. Pudiera asomarse una posible obsesión, no sólo por verse bien, sino por retar al máximo su capacidad física. Distintos autores han apuntado aristas menos favorables, que se desprenden de esta fijación por el cuerpo perfecto, entre ellos está Cortazar (2009), quien apunta lo siguiente: "Las consecuencias negativas son los peligros para la salud, por el uso masivo de esteroides anabólicos que pueden acarrear la muerte súbita” (p. 02).

Así pues, para quienes se identifican con las comunidades fitness, el fisicoconstructivismo y fisicoculturismo, representan los niveles más altos de compromiso en el levantamiento con pesas, alguna suerte de siguiente nivel, en entrenamiento por circuitos de carga y descarga, donde marcarse se logra a base de compromiso absoluto, a costa de lo que sea, hacia la concreción de la meta establecida, de hecho muchos de estos pesistas al iniciarse en este mundillo, persiguen participar en alguna competencia a escala menor, y según como resulte esta primera experiencia, pueden dejarlo allí o seguir adelante. En opinión de González (como se citó Castro et al,. 2014), ciertamente conviene tener en cuenta que: "Ante las características de estas modalidades deportivas, no es de extrañar que los fisicoculturistas y culturistas, tengan más probabilidad de padecer vigorexia, que otro tipo de colectivo social, ya que basan su vida en la constante búsqueda del cuerpo perfecto" (p. 296).

Según González (como se citó Castro et al,. 2014), “Aquellos inmersos en el mundillo del body-building, pueden exponer al peligro su salud, si por alguna razón se habitúan al uso y abuso de sustancias prohibidas, procurando encarnar un cuerpo más definido, más fuerte, más simétrico, más grande, más varonil" (p. 296). Y pues, no solo se trata de esteroides anabolizantes, en el catálogo de suplementos, también pueden contarse la creatina, proteína de suero, aminoácidos de cadena ramificada instantáneos, metabolito del aminoácido de la leucina, ZMA [Zinc, Magnesio y Vitamina B6], entre otros. Ciertamente cuando se trata de culturismo, indiferentemente de que se trate a nivel de ocio o al nivel de competencias, usualmente es relacionado al uso y abuso de sustancias, pues la realidad es que la musculatura monumental que algunos de estos atletas exhiben, no pudiera ser alcanzada sin este tipo de apoyo. Entre tanto, autores como Cortazar (2009), refieren lo siguiente:

El body-building, llamado también musculación y físico-constructivismo, se trata de moldear el cuerpo mediante el incremento de la masa muscular a través del ejercicio físico en gimnasios, 
acompañando el esfuerzo con la vigilancia dietética y la ingesta de bebidas energizantes, complementos vitamínicos y, de manera creciente, con el auxilio de esteroides anabolizantes. (p. 02)

Igualmente, autores como Flórez y Giraldo (2013), han explicado que: "El fisicoculturismo, llama la atención por ser una actividad o culto al cuerpo que lleva años practicándose pero no ha sido muy estudiada" (p. 03). Y en efecto, estas prácticas deportivas no han recibido el interés suficiente desde el enfoque social y humanista, e incluso antropológico en un sentido científico u ortodoxo, por ello, conviene resaltar el trasfondo que los valores estéticos arropan, como la motivación intrínseca de los pesista hispanos, quienes persiguen ese ideal de belleza blanca, que desde la industria cultural con origen en los países del norte ha impuesto, y de donde estos hombres extraen los modelos sociales estéticos que les interesa encarnar. Por su parte, Cortazar (2009), sostiene que: "En el body-building, se reconoce al cuerpo como una masa de arcilla que debe ser moldeada a voluntad, sometida a un diseño, hasta alcanzar la meta deseada, materia manipulable a través del ejercicio, sacrificio, junto con la química de última generación” (p. 02). Desde su lugar, Vilas (2019), ha planteado lo siguiente:

Las imágenes corporales, los conceptos acerca del cuerpo y las corporalidades mismas pueden transformarse y utilizarse como campo de justificación de prácticas e ideologías, de prescripciones y de mandatos, y al mismo tiempo funcionar como lugares donde las identidades son formadas, definidas y discutidas, en ese constante devenir que caracteriza cualquier fenómeno social. (p. 70)

Ahora bien, es muy cierto que el cuerpo masculino ha servido como vehículo donde reposa un mensaje, descifrarlo y comprenderlo compete a cada quien, pues es un tema que concierne a la arco perceptual de cada persona. Con relación a ello, surgen laudos epistémicos, qué con el propósito de reconocer tales contenidos y lograr explicarlos de forma inteligible, deben apoyarse en los hallazgos ofrecidos por otras investigaciones en ciencias sociales y humanas, que aborden la masculinidad como fenómeno de interés multidimensional; teniendo en cuenta lo descrito en todo este extenso, la comunidad de pesistas a nivel global, se elevan como el mejor contexto donde desarrollar los estudios del hombre. Por otro lado, Flórez y Giraldo (2013), ha explicado que: "Resulta fundamental conocer qué significado le otorgan los pesistas al cuerpo, desde sus experiencias personales, generadas partiendo de su realidad poliédrica, donde la interacción entre uno y otro, es una influencia importante para desarrollar conceptos, conocimientos referentes a su corporeidad" (p. 03).

Del mismo modo, Carmona (como se citó en Mejía, 2021), explica lo siguiente: "El cuerpo ha servido como medio de expresión de símbolos y por tanto es un receptor de valores, normas e ideologías, de esta manera, el cuerpo se organiza en torno a la sociedad y cultura en la que se encuentra" (p. 01). Como forma de expresión social y humana, es también muy cierto, que el cuerpo masculino ha adquirido gran relevancia en los últimos treinta años, no sólo con el advenimiento de la industria cultural, o la vorágine de los centros de musculación o los gimnasios; también, porque desde argot popular, las formas masculinas recargadas de testosterona y con dimensiones importantes, generan gran interés, curiosidad y morbo entre quienes no alimentan tabúes y si creen en el razonamiento libre. 
Así entonces, usualmente cuando se persigue auscultar el trasfondo del body-building, surgen numerosos estudios que apoyados en la estadística, exponen resultados numéricos indubitados, sobre aquello que los fisicoculturistas ejecutan in situ, es decir la forma en que combinan los circuitos de entrenamiento y los efectos que cada una de estas rutinas tienen sobre su musculatura, fuerza, vigor, o como ciertas combinaciones de ejercicios, les permite levantar más peso entre series, sin agotarse hasta cierto momento, desarrollando así más masa muscular y fuerza. Igualmente, se cuenta con diferentes investigaciones que abordan lo relativo a la nutrición de cada atleta, exponiendo tales o cuales, son los efectos que para cada uno trae determinado menú, profundizando en la composición de los alimentos sugeridos para cada dieta o regímenes alimenticios, que los pesistas adoptan durante el periodo previo a las competiciones.

Por ello, surgió el interés en los investigadores el desarrollo de un estudio que desde las ciencias sociales y humanas, como la antropología, la psicología del deporte, la sociología del deporte, la imagología, entre otras, abordasen de forma transdisciplinaria a la musculación, auscultando todo aquello que detrás de esta, ejerce gran impacto en el comportamiento del pesista hispano contemporáneo; como en efecto se ha dilucidado de alguna forma, quizás sucinta en este artículo. Respecto a ello, Minello (2002), explica lo siguiente: "Urge el desarrollo de investigaciones concretas, antropológicas, históricas, sociológicas, psicológicas y psicoanalíticas, con las características que correspondan a cada disciplina, que contemplen los aspectos materiales y simbólicos del cuerpo y sus significados" (p. 716). Desde su experiencia, Ocampo (2019a), expone lo siguiente:

Por medio del avance de los mass media y las nuevas tecnologías de la información y la comunicación, el cuerpo físico ha adquirido una nueva valoración social, fomentando una recreación del culto al cuerpo, volviéndolo un elemento de suma importancia como referente para la construcción identitaria de muchas personas. (p. 66).

Igualmente, con estudios transdisciplinarios como este, se persigue generar nuevas respuestas a cuestionamientos diferentes, respecto a fenómenos que aunque hayan sido estudiados anteriormente, no fueron abordados desde un enfoque psicosocial, integrativo, holístico, humanista, ni menos aún vinculados a otros de más larga data como el de la belleza blanca; pues tal parece que no hay muchos investigadores interesados en comprender, aquello que inspira y motiva a los pesistas a involucrarse de forma obcecada en el body-building. En opinión de Minello (2002), conviene tener en cuenta que: "Abandonar un concepto meramente empírico para convertirlo en analítico, permitirá comprender tanto el plano individual como el social, la historia y las estructuras, el cuerpo, las normas, las prácticas sociales y sus significados culturales" (p. 718). Finalmente, resulta edificante cerrar con los laudos ofrecidos por Balcazar, Berardi y Taylor (2011), quienes han referido lo siguiente: "El desafío de las Ciencias Sociales en Latinoamérica es el de promover el diálogo sobre estos temas y buscar formas de denunciar los fenómenos de racialización y prácticas de dominación arraigadas en la cultura latinoamericana" (p. 104).

\section{CONCLUSIONES}

Los expertos en antropología, sociología del deporte, psicología del deporte y la actividad física, han advertido en la motivación del ejercicio físico, un fenómeno de interés 
científico en los últimos años. Para lograr profundizar en procesos complejos como los referidos en este extenso, resulta necesario recurrir a los hallazgos generados y presentados por los estudiosos del comportamiento humano, manifestado por quienes practican alguna disciplina vinculada al levantamiento de pesas. En ese sentido, conviene tener presente que los patrones de conducta entre pesistas, están orientados por sus aspiraciones estéticas, mismas que se basan en los valores compartidos entre uno y otro como grupo humano. Para los investigadores, es preciso reconocer que los gimnasios o centros de musculación, se elevan entre los mejores contextos para el desarrollo y prolongación de investigaciones como esta; extendiendo así el campo de acción para los estudios del hombre.

Del mismo modo, con el desarrollo de investigaciones transdisciplinarias como la presente, queda claro que más que viable, resulta edificante tener en cuenta que en los centros de musculación, encuentra lugar una realidad poliédrica controvertida, susceptible de ser auscultada, intervenida, analizada e interpretada desde el paradigma postpositivista, advirtiendo que se estaría dando un abordaje completamente diferente, a los que en otrora fueron brindados a fenómenos como los referidos en todo el discurso; destacando además de la concatenación tan singular que en este estudio los investigadores lograron identificar entre fenómenos tan disímiles. Pues no se trató sólo de otro artículo más sobre body-building, belleza blanca o valores estéticos; se pudo reconocer que esta triada comparte nexos específicos y que estos son encarnados en los atletas y pesistas, varones hispanos, que como deportistas profesionales o adeptos al entrenamiento con pesas, manifiestan valores estéticos comunes y que de hecho son expuestos en sus esquemas de comportamiento social.

Por ello, se considera que la concatenación de estos fenómenos, permitirá ofrecer una visión más amplia, sobre la manera en la que los hombres hispanohablantes conciben la belleza masculina, partiendo de los modelos estéticos con origen en el norte, a los cuales aspiran ajustar su propia corporalidad, por sentirse más interesados en que se les identifique con estos, aunque biológicamente parezca absurdo; más allá de la discriminación, la auto discriminación, la xenofobia, el mito del hombre blanco superior, las desigualdades sociales en el contexto contemporáneo, la jerarquización social, como respuesta a la clasificación arbitraria con base al color de la piel, el blanqueamiento generacional como forma de eugenesia social, la transnacionalización de las culturas y los valores estéticos arraigados en el pensamiento eurocentrista, heredado por los latinoamericanos desde los colonizadores hace más de cuatrocientos años.

Ahora bien, cabe acotar que en el discurso de este artículo, los investigadores se han decantado por auscultar el trasfondo cultural, como origen de los valores estéticos que comparten algunos hombres hispanos en la contemporaneidad, y que por razones estéticas han sido apoyo para los modelos físicos aspiracionales, mismos que en el interior de los gimnasios y centros de musculación han sido retratados a través de enormes pósters, con la figura de atletas masculinos de cuerpos enormes, musculosos e icónicos, tales como Arnold Schwarzenegger referido anteriormente- quien ganó el título de Mr. Universo entre 1967 y 1970 y luego encadenó 7 victorias en la competición de Mr. Olympia entre 1970 y 1980; no obstante, resulta fundamental expresar cuan indudable es, que desde la visión de muchos atletas y deportistas, aficionados y profesionales se estrechan las desigualdades, no existen estereotipos en el contexto deportivo y atlético; cuando se trata de superar una marca o record mundial, cualquiera puede hacerlo, hombres y mujeres con origen en cualquier lugar del mundo o que pertenezcan 
a cualquier etnia, basta con ver el medallero de las últimas Olimpiadas celebradas en Tokio Japón, 2020+15, donde los récords mundiales y olímpicos, fueron impuestos incluso por mujeres hispanoamericanas, tal es el caso de Yulimar Rojas Rodríguez ${ }^{6}$ [Caracas, Venezuela, 1995], atleta especializada en triple salto, prueba con la que logró ser la campeona olímpica en 2021 — con una marca de 15,67 m, estableciendo con esto el récord mundial一.

Finalmente, puede reconocerse la complejidad social sobre la que ciernen las categorías: etnia, racialización, belleza blanca, el patriarcado, el pensamiento falocentrista y el género masculino, así como la heteronormatividad que son aprovechadas para normalizar, naturalizar e incluso romantizar las relaciones entre hombres y mujeres a favor de los varones blancos. Estas categorías representan constructos socioculturales sesgados, que dieron origen y sostienen aun hoy por hoy las diferencias de clase, etnicidad-raza, género, elongándose a través de jerarquías de poder que justifican la subordinación hacia el hombre blanco, por parte de hombres o mujeres afrodescendientes, afrocaribeños, indígenas y latinoamericanos en general, personas de estrato social precario o de las clases populares con origen en los países tercermundistas, dando lugar al sostenimiento de la clasificación social anacrónica, que desde un principio se ha apoyado en la apariencia física de los seres humanos, dificultando a los no blancos la construcción de sus propios modelos estéticos, los que deberían estar arraigados en valores culturales autóctonos.

\footnotetext{
${ }^{5}$ Oficialmente conocidos como los Juegos de la XXXII Olimpiada, tuvieron lugar del 23 de julio al 8 de agosto de 2021 en Tokio, Japón. https://olympics.com/es/olympic-games/tokyo-2020

${ }^{6}$ Yulimar Rojas Rodríguez, es una reconocida y premiada atleta profesional, nacida en Venezuela y especializada en triple salto, prueba con la que ganó el oro olímpico en Tokio 2021 - alcanzando una marca de 15,67 m- con lo cual logró imponer el récord mundial a superar. Rojas es bicampeona mundial en 2017 y 2019. En 2020 fue elegida la mejor atleta femenina del año por World Athletics, en 2021 recibió la condecoración del Trofeo Comunidad Iberoamericana de los Reyes de España, también ha sido reconocida por el Libro Guinness de los récords, pues hasta ahora es la única atleta que ha logrado el salto triple más largo de la historia, en una competencia bajo techo en la modalidad femenina año 2020: 2021.
} 


\section{REFERENCIAS}

Andréu, J. (2002). Las técnicas de Análisis de Contenido: Una revisión actualizada. Andalucía. España. Centro de Estudios Andaluces.

Arenas, L. (2017). Cuerpo y Patrimonio. Propuesta de una identidad corporal como patrimonio intangible de una sociedad. Trabajo de grado. (Publicado). Universidad Alberto Hurtado. Santiago. Chile.

Atencio, E. (2015). Gestión del conocimiento y medición del capital intelectual como recurso intangible en las organizaciones que aprenden. Análisis comparativos desde sus modelos originarios. CICAG, 13(1), 223 - 234. Recuperado en 18 de Junio de 2021 de https://publishing.fguedu.com/ojs/index.php/RSU/article/view/165/238

Balcazar, F., Berardi, L. y Taylor, T. (2011). El "privilegio de los blancos": otra fuerza de dominación social de las clases privilegiadas. Espacios en Blanco. Revista de Educación, (21),85-110. [fecha de Consulta 20 de Julio de 2021]. Disponible en: https://www.redalyc.org/articulo.oa?id=384539803004

Buitrago, R., Gutiérrez, A. y Romero, N. (2021). Inmigrantes digitales vs. nativos digitales en instituciones educativas públicas Venezolanas: Aforismos sobre una realidad poliédrica controvertida. Revista Saperes Universitas, 4(1), 6 - 38 .

Buitrago, R., Vera, J., Henríquez, C. y Gutiérrez, A. (2021). La barba como epítome de la masculinidad contemporánea ante la transgresión de los modelos sociales clásicos. IPSA Scientia, revista científica multidisciplinaria, 6(1), 36-63. https://doi.org/10.25214/27114406.1072

Castro, R., Molero, D., Cachón, J. y Zagalaz, M. (2014). Factores de la personalidad y fisicoculturismo: Indicadores asociados a la vigorexia. Revista de Psicología del Deporte, 23(2), 295-300.

Cortez, L., Escudero, C. y Cajas, M. (2017). “... Introducción a la investigación científica. C. Escudero y L. Cortez (Ed.), Técnicas y métodos cualitativos para la investigación científica. (12-25). Machala. Ecuador: Editorial UTMACH.

Cortazar, J. (2009). Reinas de belleza y Mr. Músculos. Sociología de la exhibición corporal en concursos de pasarela. XXVII Congreso de la Asociación Latinoamericana de Sociología. VIII Jornadas de Sociología de la Universidad de Buenos Aires. Asociación Latinoamericana de Sociología, Buenos Aires. Argentina.

Díaz, C. (2018). Investigación cualitativa y análisis de contenido temático. Orientación intelectual de revista Universum. Revista General de Información y Documentación, 28(1), 119-142, DOI.: http://dx.doi.org/10.5209/RGID.60813

Durán, J. y Torres, Z. (2021). Práctica de la halterofilia a edades tempranas. Consecuencias en el Crecimiento. $\begin{array}{lllllll}\text { Revista Arbitrada Interdisciplinaria } & \text { KOINONIA, } & 6(2), & 187 & - & 205 \text {, }\end{array}$ http://dx.doi.org/10.35381/r.k.v6i2.1235

Feige, K. (Productor) \& Coogler, R. (Director). (2018). Black Panther [cinta cinematográfica]. Estados Unidos: Fox Searchlight Pictures \& Marvel Studios.

Flórez, V. y Giraldo, J. (2013). Representaciones sociales de cuerpo en cuatro hombres fisicoculturista de la ciudad de Cali. Trabajo de grado (Publicado), Universidad de Buenaventura. Cali. Colombia.

Gómez, M., Galeano, C. y Jaramillo, D. (2015). El estado del arte: una metodología de investigación. Revista Colombiana de Ciencias Sociales, 6(2), 423-442.

Gómez, E., Navas, D., Aponte, G. y Betancourt, L. (2014). Metodología para la revisión bibliográfica y la gestión de información de temas científicos, a través de su estructuración y sistematización. DYNA, 81(184),158163.

Guevara, R. (2016). El estado del arte en la investigación: ¿análisis de los conocimientos acumulados o indagación por nuevos sentidos? Revista FOLIOS, (44),165-179.

Guevara, E. (2008). La masculinidad desde una perspectiva sociológica. Una dimensión del orden de género. Sociológica, 23(66), 71-92

Martín, S., y Lafuente, V. (2017). Referencias bibliográficas: indicadores para su evaluación en trabajos científicos. Investigación Bibliotecológica, 31(71), 151-180.

Martínez, O. (2020). Semiosis del "Macho" en la Cultura del Carnaval. Revista Cedotic, 5(2), 274-286.

Mejía, D. (2021). El culto al cuerpo y la opinión pública: Caso del influencer The Titan. Trabajo de grado. (Publicado). Universidad técnica de Ambato. Ambato. Ecuador.

Méndez, J. y Rico, A. (2019). Educación, cultura, estereotipos, cuerpo, género y diferencias sociales en la fotografía de moda. IE Revista de investigación educativa de la REDIECH, 9(17), 175 - 178.

Minello, N. (2002). Los estudios de masculinidad. Estudios Sociológicos, 20(3), 715-732. [fecha de Consulta 20 de Julio de 2021]. Disponible en: http://www.redalyc.org/articulo.oa?id=59806009

Morales, K. (2020). Análisis narrativo del cuerpo heterosexual en la industria cultural de la pornografía virtual (XVIDEOS.COM). Trabajo de grado (Publicado). Universidad Politécnica Salesiana. Quito. Ecuador. 
López, F. (2002). El análisis de contenido como método de investigación. XXI, Revista de Educación, 4, 167-179.

Ocampo, I. (2019a). Los nuevos cuerpos masculinos: reflexión teórica sobre los cambios identitarios en los hombres en el marco del culto al cuerpo posmoderno. EPISTEME, 11(2), 65-78.

Ocampo, I. (2019b). Itinerarios corporales masculinos en Instagram: Análisis de nuevas formas identitarias masculinas en la sociedad de consumo. Revista Punto Género, (12), 126 - 147

Ortiz, V. (2013). Modelos estéticos hegemónicos, subalternos o alternativos: una perspectiva étnico-racial de clase y género. Tabula Rasa, (18), 175-197.

Peralta, R. y Hernández, H. (2021). La neuroética como eje cardinal en la actitud gerencial del profesor universitario. SUMMA. Revista disciplinaria en ciencias económicas y sociales, 3(1), 1-34, www.doi.org/10.47666/summa.3.1.12

Prada, P. (2018). Una aproximación de un estado del arte sobre la enseñanza de la oralidad inicial. [Trabajo especial de grado publicado]. Pontificia Universidad Javeriana. Bogotá. Colombia.

Rojas, I. (2011). Elementos para el diseño de técnicas de investigación: una propuesta de definiciones y procedimientos en la investigación científica. Tiempo de Educar, 12(24), 277-297. Recuperado en 08 de Julio de 2021 de http://www.redalyc.org/articulo.oa?id=31121089006

Schongut, N. (2002). La construcción social de la masculinidad: poder, hegemonía y violencia. Psicología, Conocimiento y Sociedad, 2(2), 27-65. Recuperado en 08 de Julio de 2021 de http://www.redalyc.org/articulo.oa?id=475847408003

Sossa, A. (2015). Entrenar hasta que duela. Significaciones culturales asociadas al dolor y el cansancio en la ejercitación en gimnasios. Desacatos (48), 140-155

Vilas, L. (2019). Construcción y deconstrucción del cuerpo. Análisis de figurinas cerámicas. Una aproximación metodológica. Boletín del Museo Chileno de Arte Precolombino, 24(2), 69-87. 